Paper Number:

CONF-96092るz--1

DOE/METC/C-96/7246

Title:

Results of a Model for Premixed Combustion Oscillations

Authors:

M.C. Janus (METC)

G.A. Richards (METC)

Conference:

1996 International Symposium Combustion in Industry

RECEIVED

AUG $O>1996$

OSTI

Conference Location:

Baltimore, Maryland

Conference Dates:

September 30 - October 2, 1996

Conference Sponsor:

American Flame Research Committee

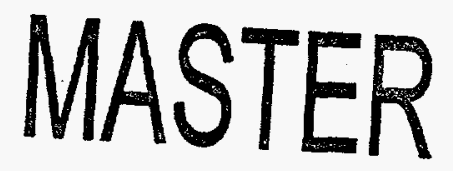




\section{DISCLAIMER}

Portions of this document may be illegible in electronic image products. Images are produced from the best available original document. 


\section{Disclaimer}

This report was prepared as an account of work sponsored by an agency of the United States Government. Neither the United States Government nor any agency thereof, nor any of their employees, makes any warranty, express or implied, or assumes any legal liability or responsibility for the accuracy, completeness, or usefulness of any information, apparatus, product, or process disclosed, or represents that its use would not infringe privately owned rights. Reference herein to any specific commercial product, process, or service by trade name, trademark, manufacturer, or otherwise does not necessarily constitute or imply its endorsement, recommendation, or favoring by the United States Government or any agency thereof. The views and opinions of authors expressed herein do not necessarily state or reflect those of the United States Government or any agency thereof. 


\title{
Results of a Model for Premixed Combustion Oscillations
}

\author{
M. C. Janus and G. A. Richards \\ U. S. Department of Energy \\ Morgantown Energy Technology Center \\ Morgantown, WV 26505
}

\begin{abstract}
Combustion oscillations are receiving renewed research interest due to the increasing application of lean premix (LPM) combustion to gas turbines. A simple, nonlinear model for premixed combustion is described in this paper. The model was developed to help explain specific experimental observations, and to provide guidance for the development of active control schemes based on nonlinear concepts. The model can be used to quickly examine instability trends associated with changes in equivalence ratio, mass flow rate, geometry, ambient conditions, and other relevant factors. The model represents the relevant processes occurring in a fuel nozzle and combustor which are analogous to current LPM turbine combustors. Conservation equations for the fuel nozzle and combustor are developed from simple control volume analysis, providing a set of ordinary differential equations that can be solved on a personal computer. Combustion is modeled as a stirred reactor, with a bi-molecular reaction rate between fuel and air. A variety of numerical results and comparisons to experimental data are presented to demonstrate the utility of the model. Model results are used to understand the fundamental mechanisms which drive combustion oscillations, the effects of inlet air temperature and nozzle geometry on instability, and the effectiveness of open loop control schemes.
\end{abstract}

\section{Introduction}

Combustion oscillations are receiving renewed research interest due to the increasing application of lean premix combustion to gas turbines. Stationary gas turbines are now commonly using premixed combustion to avoid the high levels of $\mathrm{NO}_{\mathrm{x}}$ emissions that are produced by earlier diffusion style combustors. Beer (1995) and Lefebvre (1995) provide excellent reviews of the status of LPM combustion technology. While the benefits to $\mathrm{NO}_{\mathrm{x}}$ emissions are well established, experience has shown that LPM combustion is susceptible to oscillations. Oscillating combustion should be eliminated during combustor development because associated pressure oscillations can severely damage engine hardware. As part of the Advanced Turbine Systems Program (Alsup, Zeh, and Blazewicz 1995), the U.S. Department of Energy is supporting the investigation of various solutions to this problem. Current studies include work conducted at the Morgantown Energy Technology Center (METC) as well as several university projects that are being supported through the South Carolina Energy Research and Development Center (Fant and Golan 1995).

This paper describes the development and results of a simple, nonlinear model for 
premixed combustion, referred to as PCOM (Premixed Combustion Oscillation Model). The model represents the relevant processes occurring in a fuel nozzle and combustor which are analogous to current LPM turbine combustors. As an alternative to either linear analysis or detailed modeling, this model is based on a time-dependent, nonlinear control volume analysis. A similar approach was used by Richards et al. (1993) and Narayanaswami and Richards (1995) to successfully describe experimental oscillations observed in several different styles of pulse combustors. Daw et al. (1995) showed that this type of modeling can be particularly useful to understand laboratory observations of nonlinear, chaotic behavior in oscillating combustion. Reardon (1995) developed a similar analysis to the one presented here, the primary difference being that Reardon modeled the combustion response with a specified time lag. In this paper, the combustion is modeled as a well-stirred reactor having finite kinetics. While a well stirred reactor is an obvious simplification to a premixed gas turbine combustor, it does represent a valuable limiting case.

PCOM was developed to help explain specific experimental observations (Richards et al. 1995), and to provide guidance for the development of active control schemes based on nonlinear concepts. Comparison to experimental data shows that much of the dynamic behavior observed in the lab is also predicted by this model, including the effects of inlet air temperature and some open loop control results. The model has also proven valuable to understanding the fundamental driving mechanisms of combustion instability and the effects of nozzle geometry.

\section{Model Description}

Flow properties and species concentrations in the nozzle, combustion, and tailpipe regions are determined using a control volume formulation of the conservation equations. The development is based upon the integral form of the conservation laws as presented in most texts (Moody, 1990), and also in Richards et al. (1993). PCOM assumptions include ideal gas behavior, variable specific heats, and uniform conditions within each region. The assumption of uniform conditions within each region reduces the volume and surface integrals to algebraic expressions, resulting in a set of first-order differential equations. The eight conservation equations utilized in the model are consolidated in Table 1. A thorough explanation of PCOM's development can be found in Janus and Richards (1996).

The model geometry for the premixed combustor is shown in Figure 1. A mixture of fuel and air enter the nozzle at a specified equivalence ratio and temperature. The premixed flow passes through the swirl vanes and past a so-called bypass fuel port where additional fuel can be injected. Bypass fuel is a term denoting fuel which is not included in the fuel/air mixture entering the nozzle. Bypass fuel injection may incorporate both a steady and a fluctuating component if desired. The injected fuel mixes with the nozzle mass flow in a specified volume, and continues to the end of the nozzle where it enters the combustion region. The combustion region is treated as a perfectly stirred reactor. The pressure and temperature are calculated in this region along with the oxygen and fuel mass fractions. The flow exits the combustion region into the tailpipe region, which has the same diameter as the combustor. 


\section{Nozzle Region}

The inlet boundary of the nozzle can be set to one of two distinct conditions. One condition specifies the temperature, equivalence ratio and pressure, and allows the mass flow rate to fluctuate. The other condition sets the temperature, equivalence ratio, and mass flow rate, and allows the inlet pressure to fluctuate. This latter condition is equivalent to a choked fuel/air inlet, and will be modeled here for comparison to experimental data described later.

Fluid motion in the nozzle can be described as unsteady plug flow for most cases of interest due the relative length of the LPM nozzle compared to the applicable acoustic lengths. The nozzle swirl vanes are treated as an ideal cascade, producing no change in entropy. The vanes are positioned at $45^{\circ}$ from the nozzle axis, and flow through the vanes is assumed incompressible due to the low Mach numbers expected in the nozzle. Derivation of the nozzle momentum balance assumes a quasi-steady friction force, adiabatic walls, spatially uniform density, and unsteady plug flow. It should also be noted that the analysis is limited to positive nozzle velocities only. Detailed CFD modeling and experimental testing show this approximation to be valid for most cases of interest. Extreme pressure oscillations at low flow rates may invalidate the assumption.

An additional simplifying assumption of the model is that mass addition from the bypass port is neglected in the momentum conservation equation. The mass flow of injected fuel is typically less than 20 percent of the total fuel flow, which is less than 6 percent of the total air flow. Thus, the momentum balance neglects 1.2 percent of the nozzle mass flow. Note that short pulse width, low frequency, or high bypass mass flow may invalidate this assumption. Although the effect of bypass fuel injection is neglected in the momentum balance, the fuel mass fraction must be tracked downstream of the bypass port. The assumption of positive velocity negates the need to calculate the fuel mass fraction upstream of the bypass port. A simple, onedimensional finite difference grid is established for the post-bypass section of the nozzle. Fuel mass fraction is calculated at each grid point using a simplified version of the method of characteristics in which only the position of the pathlines are tracked. Note that fuel injection through the bypass port is considered choked, and is therefore unaffected by downstream pressure fluctuations.

\section{Tailpipe Region}

Flow in the tailpipe region is also modeled as unsteady plug flow. The tailpipe region is the same diameter as the combustor. Note that tailpipe flow is not restricted to positive velocities, and may therefore reverse into the combustion region.

\section{Combustion Region}

Properties within the combustion region are calculated using the conservation of mass, momentum and energy, species conservation for fuel and oxygen, and the ideal gas law. Combustion is modelled as a bi-molecular reaction. Fuel and oxygen react at a rate determined by a one-step Arrhenius kinetic mechanism. Fuel properties used in the model are those of methane. 


\section{Numeric Solution of the Governing Equations}

Solution of these equations is obtained by applying the Euler predictor-corrector algorithm. The solution method is straightforward and involves direct marching from one time to the next. The simulation is started by simply specifying a high initial temperature. Depending on the geometry and operating conditions, combustion will continue as a steady flame, blow out, or oscillate. It is emphasized that this model will predict any of these responses depending on the conditions specified. Periodic heat release is not imposed.

The solution speed of PCOM is relatively fast. Given a simple combustor geometry and a specified time step, a CFD model running on an SGI Indigo ${ }^{2}$ machine with a R400 MIPS processor could take over 30 days to simulate a single second of combustion. In comparison, PCOM running on a personal computer with a $100 \mathrm{MHz}$ Pentium processor can simulate a second of combustion in less than 15 minutes.

\section{Experimental Description}

PCOM simulations are based upon the experimental rig shown in Figure 2. This atmospheric pressure combustion rig is designed to handle multiple premix fuel nozzles. The 7.6 $\mathrm{cm}$ O.D. combustor body is constructed of quartz and is mounted inside a $36 \mathrm{~cm}$ O.D. steel containment pipe. The multiple viewing ports of the containment pipe allow complete optical access to the flame zone. Oscillations are typically excited around $300 \mathrm{~Hz}$, which is the approximate quarter wavelength of the $0.6 \mathrm{~m}$ combustor body.

A detailed sketch of the premixed, swirl stabilized fuel nozzle is shown in Figure 3. A central $12.7 \mathrm{~mm}$ stainless steel tube supplies premixed fuel and air to the pilot flame on the nozzle axis. The pilot flame is lit with an internal spark electrode approximately $57 \mathrm{~mm}$ upstream of the nozzle exit. Note that for the results to be discussed, the pilot is only used during start-up and not during testing. The pilot tube is surrounded by the lean premix fuel and air. The lean premixture enters the nozzle through two diametrically opposed tubes $21 \mathrm{~cm}$ upstream of the nozzle exit. The premixed fuel and air pass through a wire mesh flow straightener and then through straight finned swirl vanes angled 45 degrees from the nozzle axis. The fuel and air are mixed approximately $100 \mathrm{~cm}$ upstream of the nozzle to ensure thorough mixing.

Multiple injection ports for premix fuel are provided along the nozzle length. Fuel flow through each injection port is individually metered. The bypass fuel entering through the injection ports may be choked at the nozzle interface or further upstream, depending upon the

goal of the experiment. The length of the tubing between the choke point and the fuel nozzle is adjustable. This length is critical because acoustic resonance in the tube can contribute to the combustion oscillations (Richards, 1996). The port is choked at the nozzle interface when testing for instabilities due to air supply variation.

Unsteady pressure is measured using a piezoelectric pressure transducer mounted on the nozzle exit flange, very near the flame zone. Thermocouples measure the temperature of fuel 
and air mixture just before it enters the nozzle, and the gas temperature at the exit of the combustor body. Time varying heat release is recorded with a fiber optic $\mathrm{OH}$ emission probe inside the containment pipe downstream of the combustor.

\section{Results}

The simple model described is valuable to understand the origin of combustion instabilities and the various means to control them. One can quickly examine instability trends associated with changes in equivalence ratio, mass flow rate, geometry, ambient conditions, and other relevant factors. PCOM obviously has somewhat limited use as a precise design tool due to its simplicity. Experimental evidence has shown that multiple, interdependent mechanisms affect the stability performance of a combustor, and. not all of these complicated mechanisms are captured by the model. As an example, experimental results have shown that a pilot flame can have significant effects upon the stability of a combustor. The behavior of a pilot flame cannot be modeled in a stirred reactor. Given these limitations, PCOM has nonetheless proven valuable to the study of LPM combustion instability.

\section{Combustion Instability Mechanisms}

A combination of experimental testing and numeric simulation has helped identified five mechanisms that can drive combustion instability. These mechanisms are fuel supply variation, mixture supply variation, air supply variation; pilot instability, and swirl instability (see Richards (1996) for a detailed explanation of the various instability mechanisms). One instability mechanism that PCOM has been especially helpful in clarifying is air supply variation. Instabilities via air supply variation occur when pressure fluctuations in the combustor produce corresponding changes in the nozzle air flow. Given a constant fuel flow, the result is a time varying fuel/air ratio. This fluctuation in the fuel/air ratio creates a fluctuation in the reaction rate, which results in an oscillatory heat release. If the resultant heat release fluctuation is in phase with the acoustic pressure, the feedback loop is closed and a limit cycle oscillation may be attained.

For these experiments, all of the LPM air and a majority of the LPM fuel are premixed upstream and enter the nozzle through the LPM ports. A small percentage of the LPM fuel enters through a bypass port which is choked at the nozzle interface. Note that for both the experimental and numerical data, a mixture supply instability often accompanies the air supply instability.

Figure 4 shows the RMS pressure in the experimental combustor versus the bypass port position for an air flow rate of $17 \mathrm{~g} / \mathrm{s}$ and an equivalence ratio of 0.7 . The "No Bypass" data is a baseline measurement which indicates the level of instability when no fuel passes through the bypass port. An oscillation at the baseline level is usually caused by a mixture supply variation. Although the overall equivalence ratio is constant, the oscillation magnitude varies around the baseline level as the axial position of the bypass port is altered. This variation is due to air

supply instability. Model results are shown in figure 5. A similar fluctuation around the baseline level is exhibited. The variation in the RMS pressure is due to changes in the fuel 
transport time. The transport time is defined as the total amount of time it takes for a pocket of fuel to advect down the nozzle to the flame front, effectively mix, and subsequently combust. Transport time is the summation of advection time, mixing time, and reaction time. If the transport time is such that a fuel "pocket" generates heat at the peak of combustor pressure, the oscillation will be reinforced. Note that the model predicts that the axial position at which oscillations are damped is further downstream than the experiment indicates. This is to be expected because the stirred reactor model neglects the mixing portion of the transport time. Given a specific set of operating conditions, oscillating frequency, and bypass port location, the model will predict a shorter transport time than occurs in the experiment. This explains why the axial port location which damps the oscillation is further upstream in the model.

Figures 6 and 7 respectively show experimental and numerical RMS pressure versus bypass port location for an air flow rate of $18.9 \mathrm{~g} / \mathrm{s}$ and an equivalence ratio of 0.7 . The figures indicate that the axial location that damps the oscillation is moved further upstream as the air flow rate is increased. Given that the oscillating frequency is relatively constant from $17 \mathrm{~g} / \mathrm{s}$ to $18.9 \mathrm{~g} / \mathrm{s}$, this result is to be expected since the increase in nozzle velocity decreases the transport time.

\section{Nozzle Geometry}

Geometry has been shown to be a dominant factor in determining the stability of a fuel nozzle. Even slight machining tolerances have the potential to cause varying stability behavior. PCOM is valuable to understanding the effect of some simple geometrical changes. Figure 8 shows how a slight decrease $(1.5 \%)$ in nozzle diameter can affect the stability of a nozzle. Note that the data in Figure 5 serves as the baseline (air flow $=17 \mathrm{~g} / \mathrm{s}$ and equivalence ratio $=0.7$ ). Figure 8 indicates that the axial port which most efficiently damps the oscillation is moved upstream as the nozzle diameter is decreased. The decrease in nozzle area has increased the nozzle velocity for a given flow rate, and therefore increased the transport time to the combustor.

It should be noted that an instability associated with air supply variation, as depicted in Figures 5 and 8 , is not the only mechanism which could be affected by a change in geometry. For example, a modest change to the diameter or the length of a fuel nozzle will alter the nozzle impedance at the combustor interface and thereby alter the characteristics of an instability due to mixture supply variation. Figure 9 shows the effect of a $7.5 \%$ decrease in the nozzle diameter. This significant geometrical change has moved the nozzle in to a fairly stable regime, as indicated by the "No Bypass" data. The instability due to mixture feed variation is no longer present.

\section{Open Loop Control}

Combustion oscillation control using low frequency, cyclic fuel injection was successfully tested on the experimental combustor shown in Figure 2. A complete description of the experiment and details of the combustor configuration can be found in Richards, et al. (1995). A time history of a pressure signal from the combustor with no cyclic fuel injection is shown in Figure 10. A $4.5 \mathrm{kPa}$ RMS pressure signal is established at $300 \mathrm{~Hz}$ given premix fuel and air flow rates of $0.4 \mathrm{~g} / \mathrm{s}$ and $9.9 \mathrm{~g} / \mathrm{s}$, respectively. Figure 11 shows model results using a similar 
geometry and operating conditions. A $4.0 \mathrm{kPa} \mathrm{RMS}$ pressure signal is established at approximately $280 \mathrm{~Hz}$.

Active control of the oscillation using low frequency injection was attempted by adding $0.067 \mathrm{~g} / \mathrm{s}$ of fuel through the pulse injector. The fuel injector was operated with a frequency of $50 \mathrm{~Hz}$ and a pulse width of $7 \mathrm{~ms}$. The resulting pressure oscillation of the combustor along with the injector status is shown in Figure 12. A step in the injector signal signifies the injector is open. The low frequency injection is shown to decrease the pressure oscillation by a factor of 0.3 from the uncontrolled case shown in Figure 10. Figure 13 shows model results using a low frequency injection through the bypass port. Pressure oscillations are shown to decrease by a comparable percentage.

Figure 14 shows a time history of the pressure signal and the injector status from the time at which the injected fuel is first introduced into the nozzle until the oscillations are significantly suppressed. The model demonstrates that under these specified conditions, the limit cycle can be broken by periodically altering the equivalence ratio. The low frequency fuel injection is able to break the limit cycle by shifting combustion back and forth between stable and unstable conditions. This was demonstrated numerically by observing the oscillating behavior at (steady) equivalence ratios representing the instantaneous conditions corresponding to the injector open or closed states. Experiment and model both show that a relatively small amount of fuel injected appropriately can break a limit cycle and thus stabilize combustion oscillations.

\section{Inlet Air Temperature}

Initial difficulties in repeating experimental data from day to day led to the identification of inlet air temperature as a relevant parameter in combustion instability research. Although differences in inlet air temperature were severely affecting oscillation levels, the root cause was not immediately apparent. Figure 15 shows experimental and numerical data from a combustor similar to the one shown in Figure 2 operating at an equivalence ratio of 0.75 and an air flow rate of $19.3 \mathrm{~g} / \mathrm{s}$. The only parameter altered in Figure 15 is the temperature of the fuel and air mixture entering the nozzle. Experimental data shows that a significant increase in the pressure oscillation occurs at approximately $283 \mathrm{~K}$. Numerical data shows a more severe, yet similar transition at approximately $293 \mathrm{~K}$.

It should be noted that the simplicity of the model in conjunction with the multiple, interdependent instability mechanisms previously alluded to make exact prediction of an experimental temperature transition very difficult. Nonetheless, a better understanding of the root cause of the transition is provided by the model. The model demonstrates that changes in air temperature will alter reaction rates, and even nozzle velocities to a lesser extent. As the inlet air temperature increases, the reaction rate will increase and the nozzle velocity will also slightly increase. Both of these responses to an increasing inlet temperature result in a decrease in the transport time. The change in transport time could possibly move the combustor from a stable to an unstable region, or vice-versa. Figures 16 and 17 show the effect of inlet air temperature as air flow rate and equivalence ratio are respectively changed. A change in inlet air temperature has a varied effect on each of the cases modeled, as would be expected. Figure 
10 shows that flow at $29.4 \mathrm{~g} / \mathrm{s}$ is highly stable and that modest changes in temperature will not have an effect. Flow at $9.1 \mathrm{~g} / \mathrm{s}$, on the other hand, is highly unstable, but inlet air temperature changes can still not alter the transport time significantly enough to move the flow out of the unstable region. As previously alluded to, flow at $19.3 \mathrm{~g} / \mathrm{s}$ experiences a transition at approximately $293 \mathrm{~K}$ and $353 \mathrm{~K}$.

\section{Conclusions}

As an alternative to linear analysis or detailed modeling, a simple, nonlinear model for premixed combustion has been developed to help explain experimental observations and to provide guidance for the development of active control schemes. PCOM represents the relevant processes occurring in a fuel nozzle and combustor which are analogous to current LPM turbine combustors. Conservation equations for the fuel nozzle and combustor are developed from control volume analysis, providing a set of ordinary differential equations that can be solved on a personal computer.

The model can be used to quirckly examine instability trends associated with changes in equivalence ratio, mass flow rate, geometry, ambient conditions, and other relevant parameters. PCOM will have somewhat limited use a design tool due to its simplicity. Given its limitations, the model has nonetheless proven valuable to our understanding of LPM combustion instability. Comparison to experimental data shows that much of the dynamic behavior observed in the lab is also predicted by PCOM, including the effects of inlet air temperature and some open loop control results. PCOM has been a valuable tool to understanding the fundamental mechanisms which drive combustion oscillations. 


\section{Nomenclature}

Note: the text uses an overbar to denote the normalized counterpart of variables listed here. The normalizing factor is listed with the variables below.

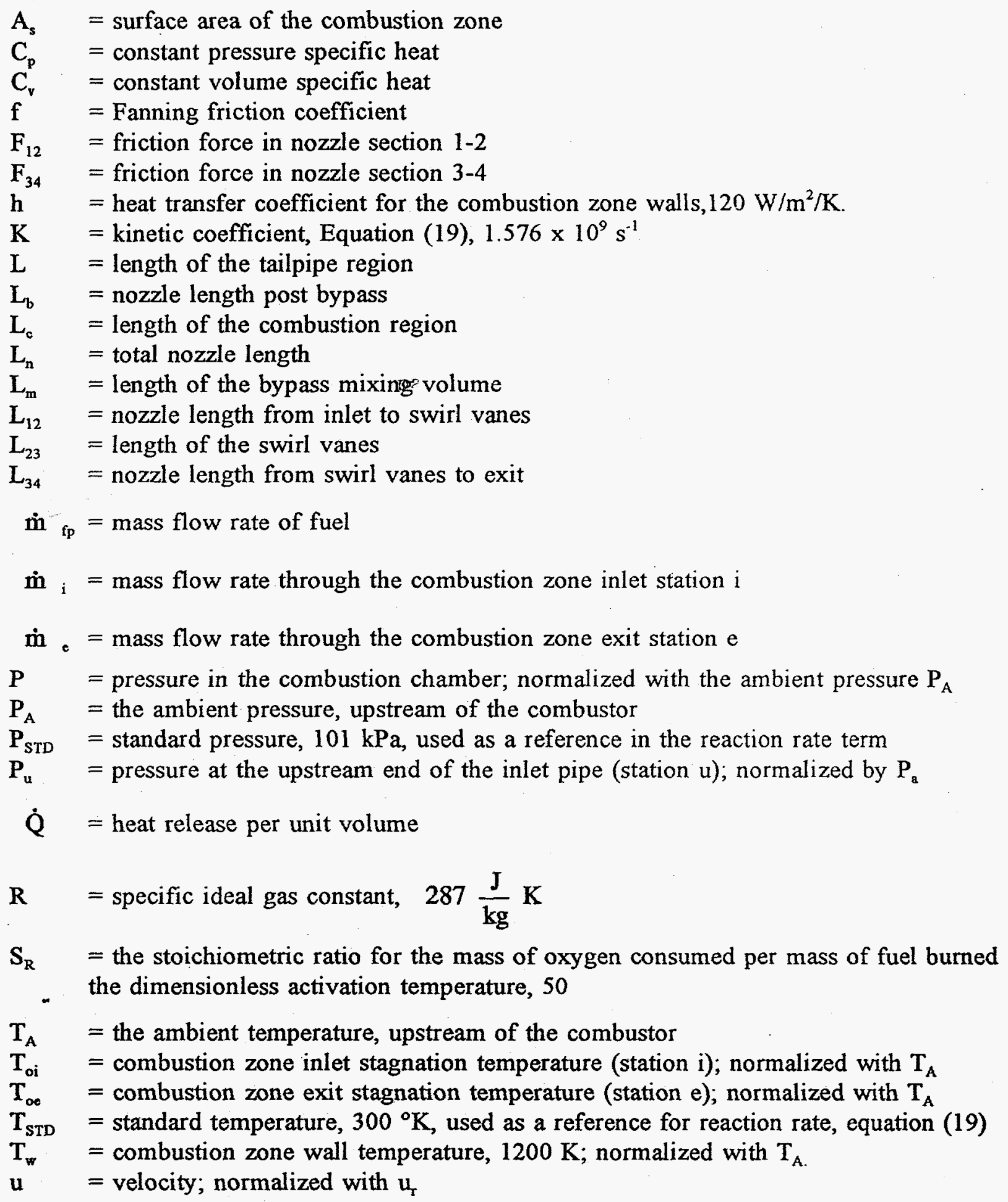




$$
\begin{array}{ll}
u_{\mathrm{r}} & =\text { reference velocity; } \sqrt{\mathrm{RT}} \\
\mathrm{V}_{\mathrm{c}} & =\text { combustion region volume } \\
\mathrm{V}_{\mathrm{m}} & =\text { bypass port mixing volume } \\
\mathrm{Y}_{\mathrm{f}} & =\text { fuel mass fraction in combustion zone } \\
\mathrm{Y}_{\mathrm{fb}} & =\text { fuel mass fraction at the bypass port } \\
\mathrm{Y}_{\mathrm{fi}} & =\text { fuel mass fraction, combustion zone inlet, station } \mathrm{i} \\
\mathrm{Y}_{\mathrm{o}} & =\text { oxygen mass fraction in combustion zone } \\
\mathrm{Y}_{\mathrm{oi}} & =\text { oxygen mass fraction, combustion zone inlet, station i } \\
\rho & =\text { combustion region density } \\
\rho_{\mathrm{A}} & =\text { ambient density } \\
\rho_{\mathrm{b}} & =\text { nozzle density at the bypass port } \\
\rho_{12} & =\text { nozzle density in section } 1-2 \\
\rho_{23} & =\text { nozzle density in section } 2-3 \\
\rho_{34} & =\text { nozzle density in section } 3-4 \\
\gamma & =\text { ratio of specific heats } \\
\tau_{\mathrm{c}} & =\text { combustion time } \\
\tau_{\mathrm{c}} & =\text { exit flow time } \\
\tau_{\mathrm{HT}} \quad=\text { heat transfer time } \\
\tau_{\mathrm{i}} \quad=\text { inlet flow time } \\
\tau_{\mathrm{m}} \quad=\text { mixing time } \\
\Delta \mathrm{H}, \quad=\text { fuel heat of combustion per unit mass } 5 \times 10^{7} \frac{\mathrm{J}}{\mathrm{kg}}
\end{array}
$$




\section{References}

Alsup, C.T., C.M. Zeh, and S. Blazewicz, eds. 1995. Proceedings of the Advanced Turbine Systems Annual Program Review Meeting. 2 vols. DOE/METC-96/1023. NTIS/DE96000561 and NTIS/DE96000562. Springfield, Va.: National Tehnical Information Service.

Beer, J. M. (1995). Clean Combustion In Gas Turbines: Challenges and Technical Response - a Review, Journal of the Institute of Energy, March 1995, pp. 2-10.

Benelli, G., V. Cossalter, and M. Da Lio (1993). Advances in Numerical Simulation of Pulsating Combustion at ENEL, Combustion Science and Technology, Vol. 94, pp. 317 - 335.

Crocco, 1., and Cheng, S. I., Theory of Combustion Instability in Liquid Propellant Rocket Motors, AGARD monograph, No. 8, Butterworths, London, 1956.

Culick, F. E. C. (1994). Some Recent Results for Nonlinear Acoustics in Combustion Chambers, ALAA Journal, Vol. 32, No. I pp. 146 - 169.

Daw, C. S., J. F. Thomas, G. A. Richards, L. L. Narayanaswami (1995). Chaos in Thermal Pulse Combustion, Chaos, Vol. 5 , No. 4, pp $662-670$.

Lefebvre, A. H. (1995). The Role of Fuel Preparation in Low Emission Combustion, ASME Journal of Engineering For Gas Turbines and Power, October 1995, Vol. 117, pp. 617 - 654.

Menon, S. (1994) Secondary Fuel Injection Control of Combustion Instability in a Ramjet, Combustion Science and Technology, Vol. 100, pp. 385-393.

Menon, S., and Jou, W. H. (1991). Large-Eddy Simulations of Combustion Instabilities in an Axisymmetric Ramjet Combustor, Combustion Science and Technology, Vol 84, pp. 51-79.

Merk, H. J., (1956). An Analysis of Unstable Combustion of Premixed Gases Sixth Symposium (International) on Combustion, The Combustion Institute, Pittsburgh, PA, pp. $500-512$.

Moody, F. J., 1990, Introduction to Unsteady Thermofluid Mechanics, John Wiley \& Sons Publishing.

Najm, H. N., and A. F. Ghoniem (1993). Modeling Pulsating Combustion Due to Flow-Flame Interactions in Vortex-Stabilized Pre-Mixed Flames. Combustion Science and Technology, Vol. 94, pp. 259 - 278.

Narayanaswami, L. L., and G. A. Richards (1995). Pressure Gain Combustion, Part I: Model Development, to appear in ASME Journal of Engineering for Gas Turbines and Power. See also G. A. Richards, R. S. Gemmen, and L. L. Narayanaswami (1994). Aerovalve Pulse Combustion, DOE/METC94/1009 (DE94012262).

Parks, W. P. \{ed.\}, (1994). Proceedings of the Advanced Turbine Systems Annual Program Review Meeting, Nov. 9-11, 1994, Arlington VA., DOE/OR-2025.

Putnam, A. A., and W. R. Dennis (1953). Organ Pipe Oscillations in a Flame Filled Tube, Fourth Symposium (International) on Combustion, The Combustion Institute, Pittsburgh, PA, pp. 566 - 575.

Reardon, F. H. (1989). Very Low-Frequency Oscillations in Liquid Fuel Ramjets, in Combustion 
Instabilities in Liquid Fueled Propulsion Systems, NATO AGARD Conference Proceeding No. 450.

Reardon, F. H. (1995). Nonlinear Dynamics Model of a Pulsating Combustion System, Proceeding of the 34th Heat Transfer and Fluid Mechanics Institute June 1-2 1995, California State University, Sacramento, CA.

Richards, G. A. and Yip, M.J. (1995). Oscillating Combustion from a Premix Fuel Nozzle, Combustion Institute/American Flame Research Committee Meeting Proceedings April 23-26, 1995, San Antonio, TX.

Richards, G. A., M. J. Yip, E. Robey, L. Cowell, and D. Rawlins (1995). Combustion Oscillation Control by Cyclic Fuel Injection, to appear in ASME Journal of Engineering for Gas Turbines and Power. Presented as ASME paper 95-GT-224.

Richards, G. A. , G. J. Morris, D. W. Shaw, S. A. Keely, and M. J. Welter (1993). Thermal Pulse Combustion, Combustion Science and Technology, Vol. 94, pp. 75-85, 1993.

Yu, K. H., A. Trouve, and J. W. Daily (1991). Low Frequency Pressure Oscillations in a Model Ramjet Combustor, Journal of Fluid Mechanics, Vol. 232, pp. 47 - 72. 
Table 1. Conservation Equations for the Premixed

Combustion Oscillation Model (PCOM)

Nozzle Region Equations

$$
\begin{gathered}
\frac{d \bar{u}_{n}}{d t}=\left(\bar{P}_{u}-\bar{P}\right) \frac{\sqrt{R T_{A}}}{L_{n}}-\frac{\sqrt{R T_{\Lambda}}}{L_{n}} \frac{\bar{u}_{n}^{2}}{2}\left[1+\frac{L_{n}}{D_{n}} f\right] \\
\frac{d Y_{f, b}}{d t}=\frac{1}{\tau_{m}} \bar{u}_{n}\left(Y_{f, u}-Y_{f, b}\right)+\frac{1}{\tau_{m}} \frac{\dot{m}_{f, b}}{\rho_{A} A_{n} \sqrt{R T_{A}}}\left(1-Y_{t, b}\right)
\end{gathered}
$$

Tailpipe Region Equations

$$
\frac{d \bar{u}}{d t}=\frac{\sqrt{R T_{A}}}{L}\left[\frac{\bar{P}-1}{\bar{\rho}}-\frac{f}{2} \frac{L_{c}}{D_{c}} \frac{\vec{u}}{|\bar{u}|}\right]
$$

Combustion Region Equations

$$
\begin{gathered}
\frac{d \bar{P}}{d t}=\gamma\left[\frac{\bar{T}_{o i}}{\tau_{i}}-\frac{\bar{T}_{o c}}{\tau_{c}}\right]+\frac{(\gamma-1)}{\tau_{c}}+\frac{(\gamma-1)}{\tau_{H T}}\left(\bar{T}_{w}-\bar{T}\right) \\
\frac{d \bar{\rho}}{d t}=\frac{1}{\tau_{i}}-\frac{1}{\tau_{c}} \\
\frac{d Y_{f}}{d t}=\frac{1}{\tau_{i} \bar{\rho}}\left(Y_{f, i}-Y_{f}\right)-\frac{R T_{A}}{\Delta H_{f}} \frac{1}{\bar{\rho}} \frac{1}{\tau_{c}} \\
\frac{d Y_{o x}}{d t}=\frac{1}{\tau_{i} \bar{\rho}}\left(Y_{o x, i}-Y_{o x}\right)-\frac{R T_{A}}{\Delta H_{f}} \frac{1}{\bar{\rho}} \frac{1}{\tau_{c}} S_{r} \\
\bar{P}=\bar{\rho} \bar{T}
\end{gathered}
$$




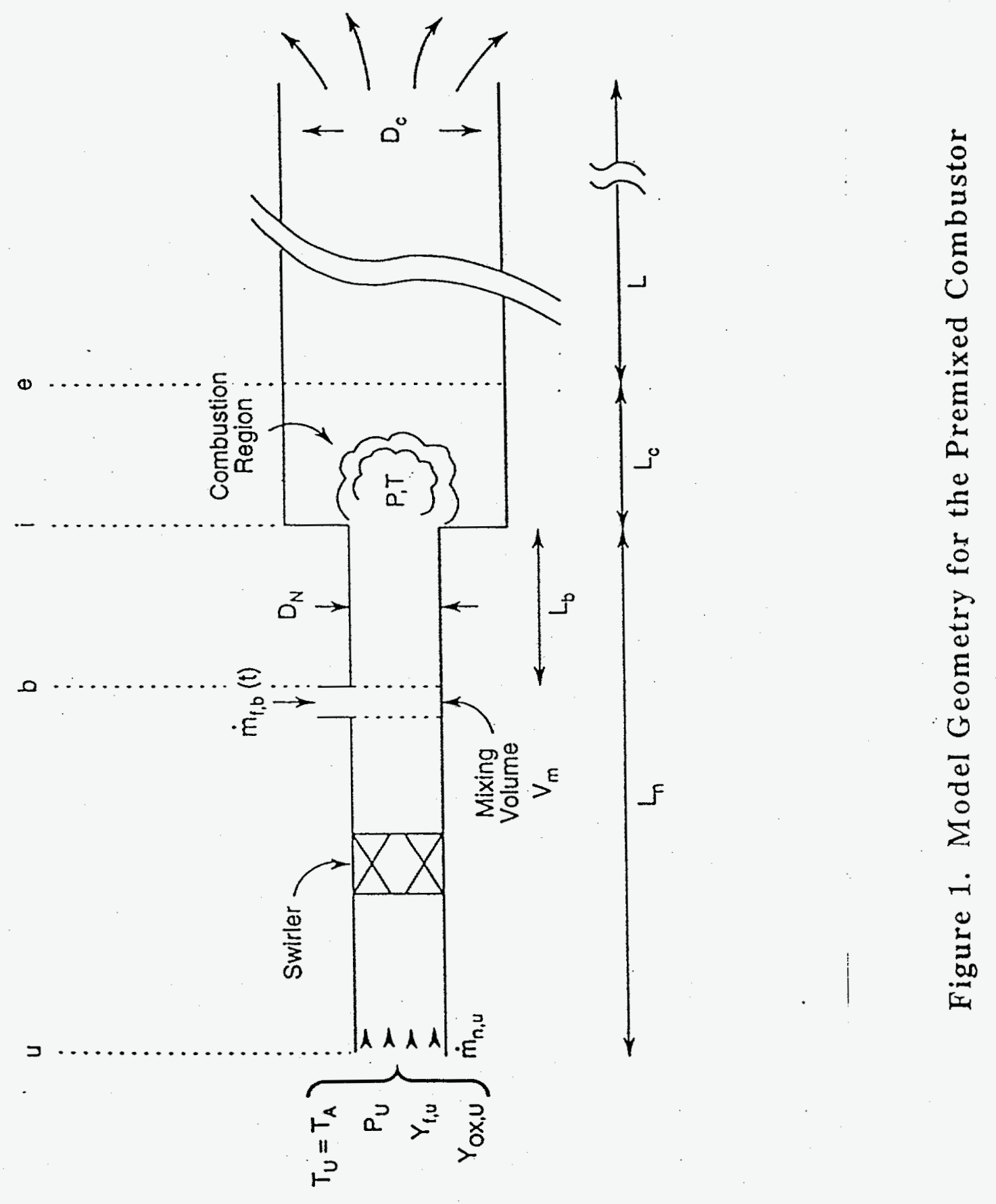




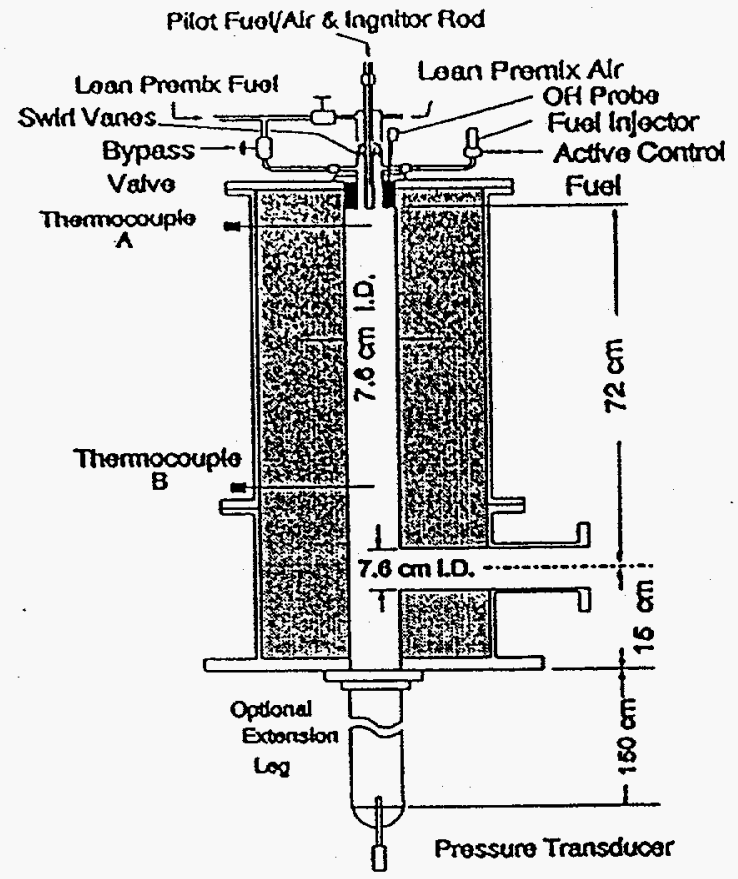

FIG. 2. EXPERIMENTAL CONFIGURATION.

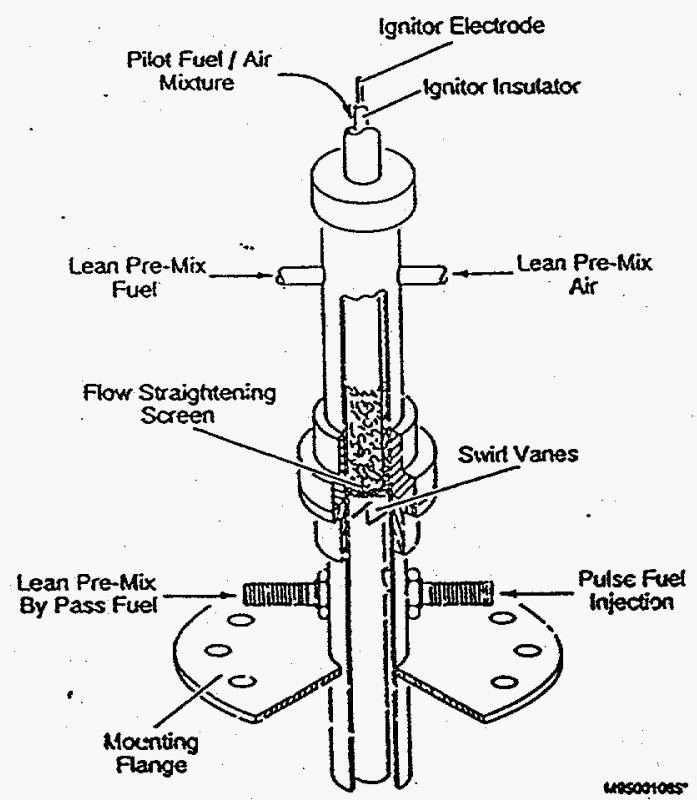

FIG. 3. DETAILED VIEW OF THE PREMIX FUEL NOZZLE. 


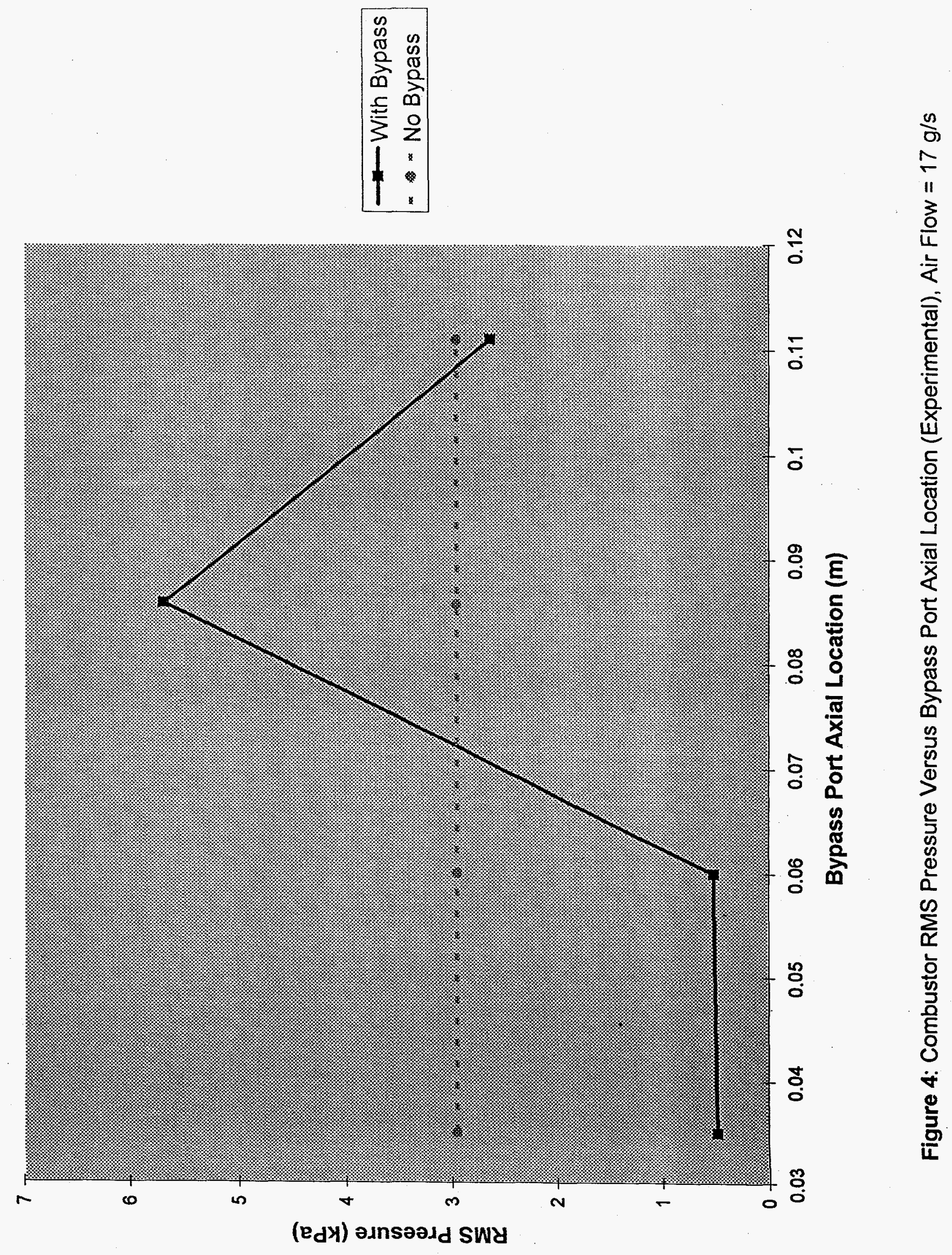




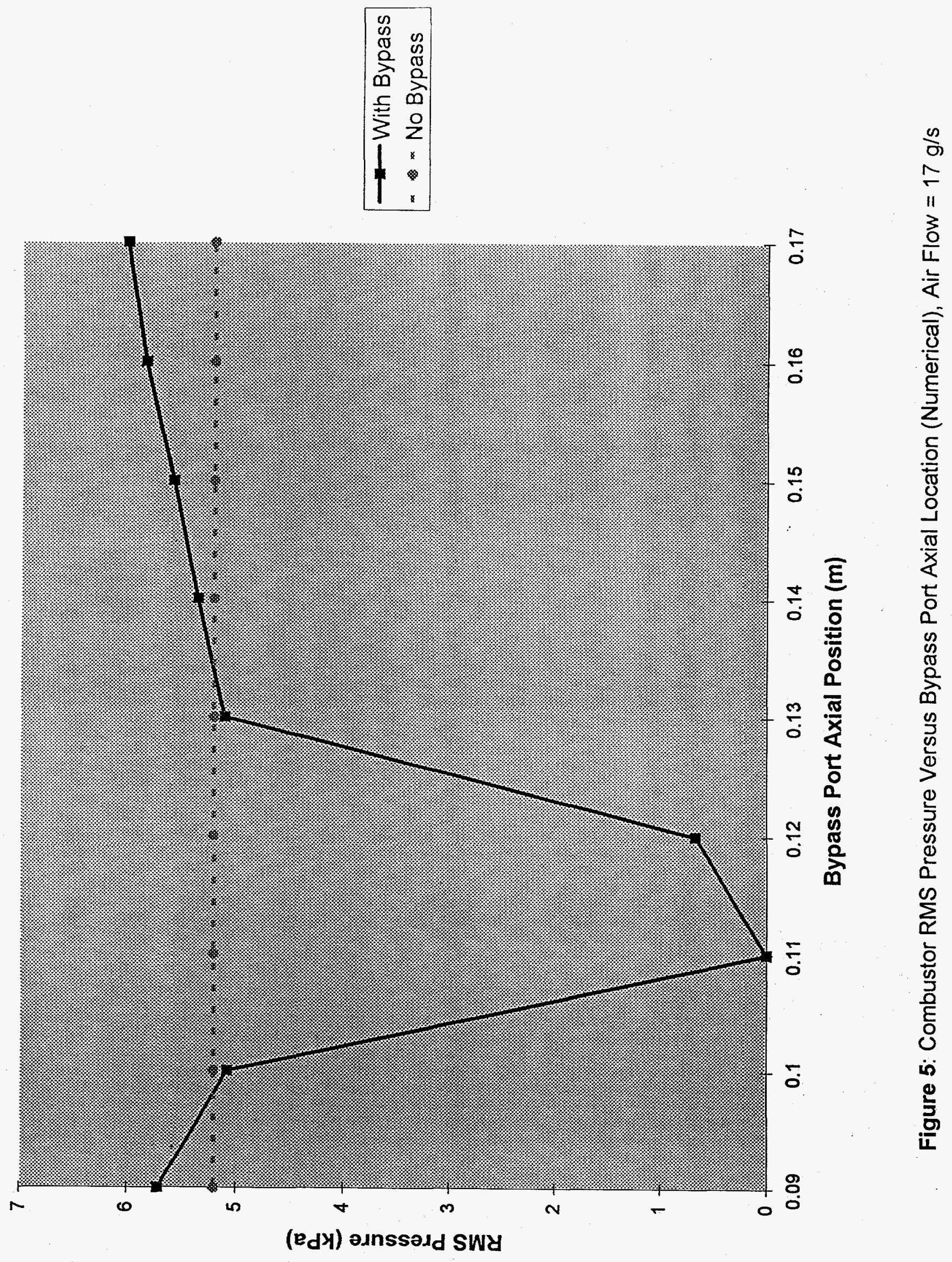




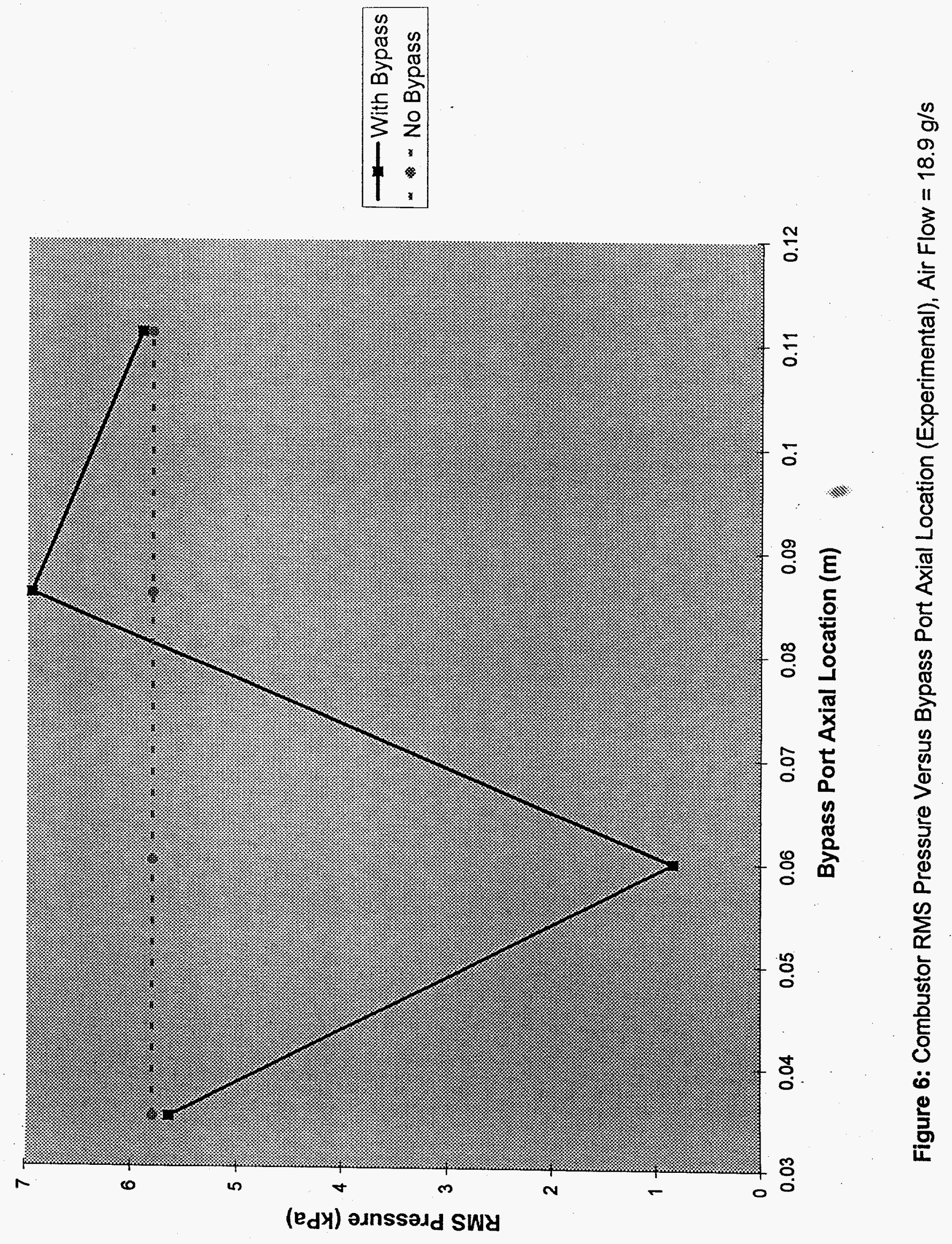




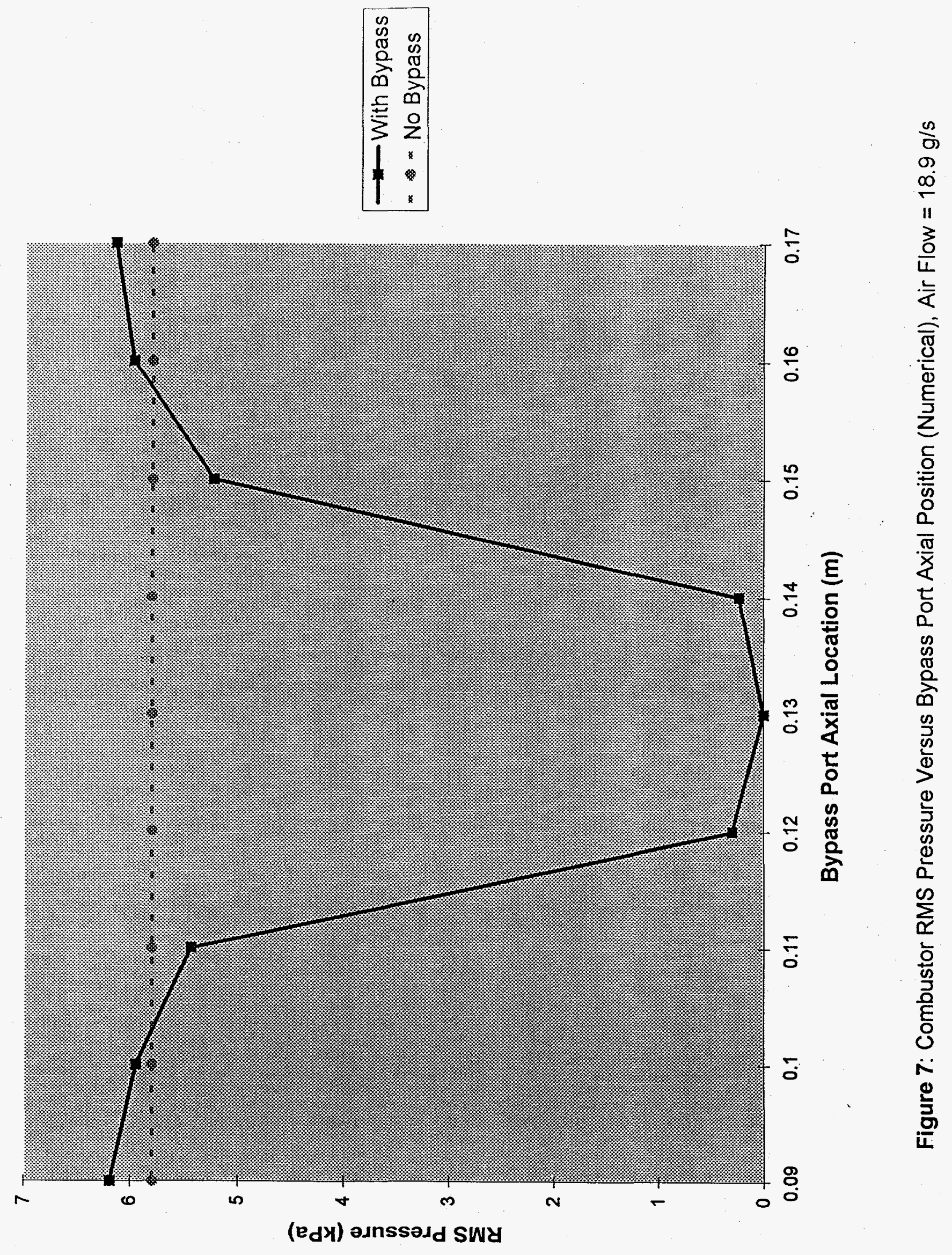




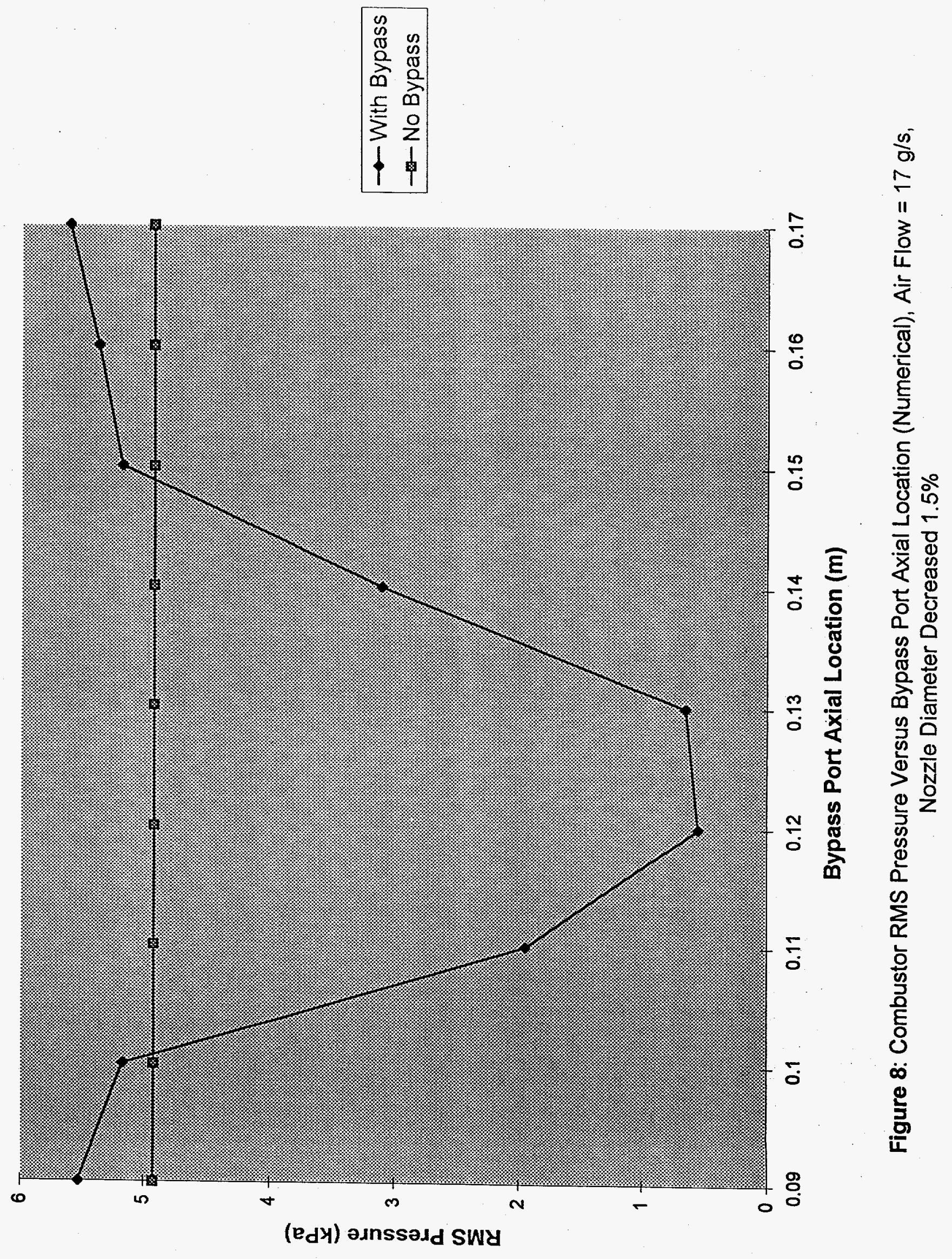




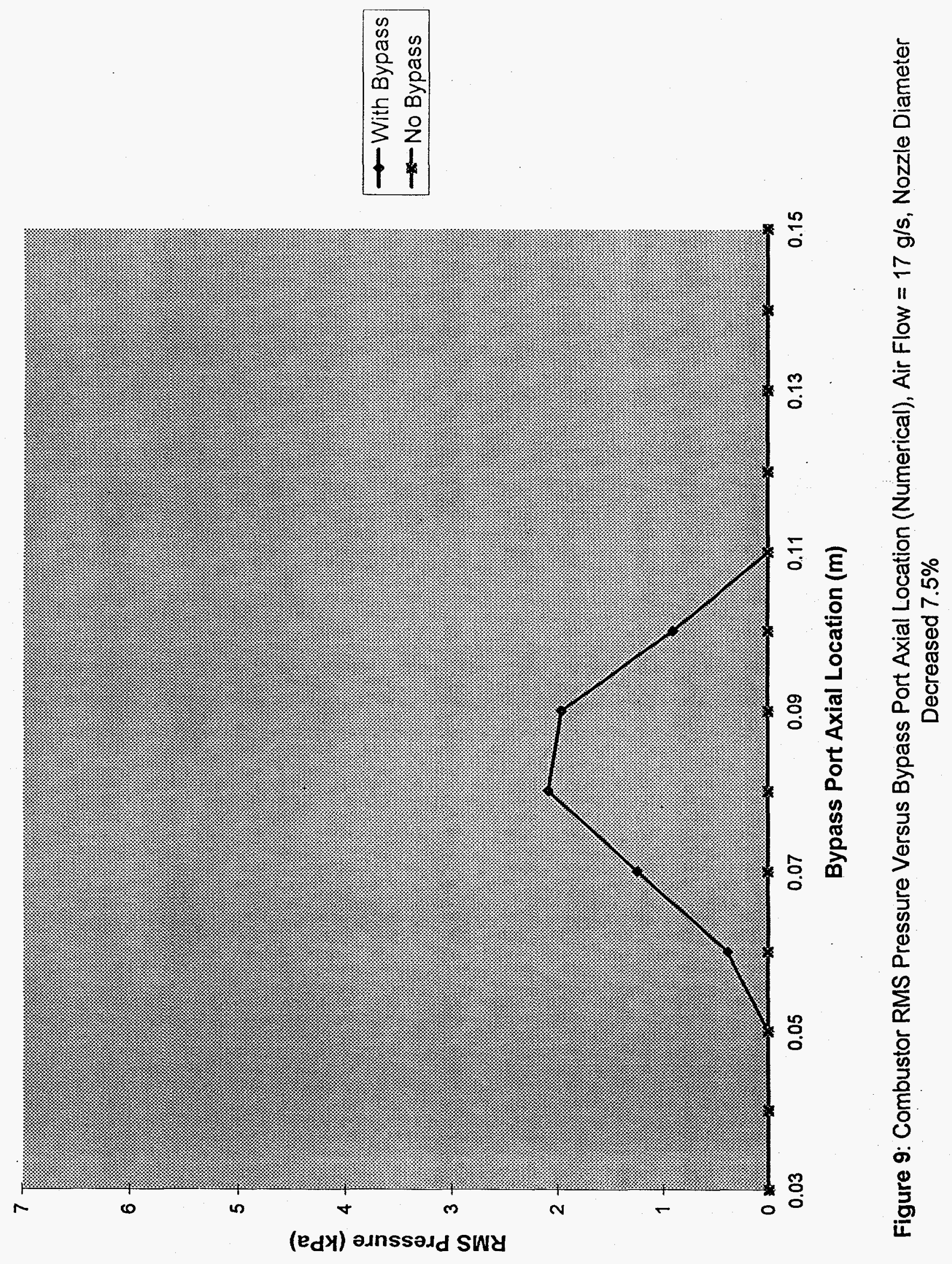




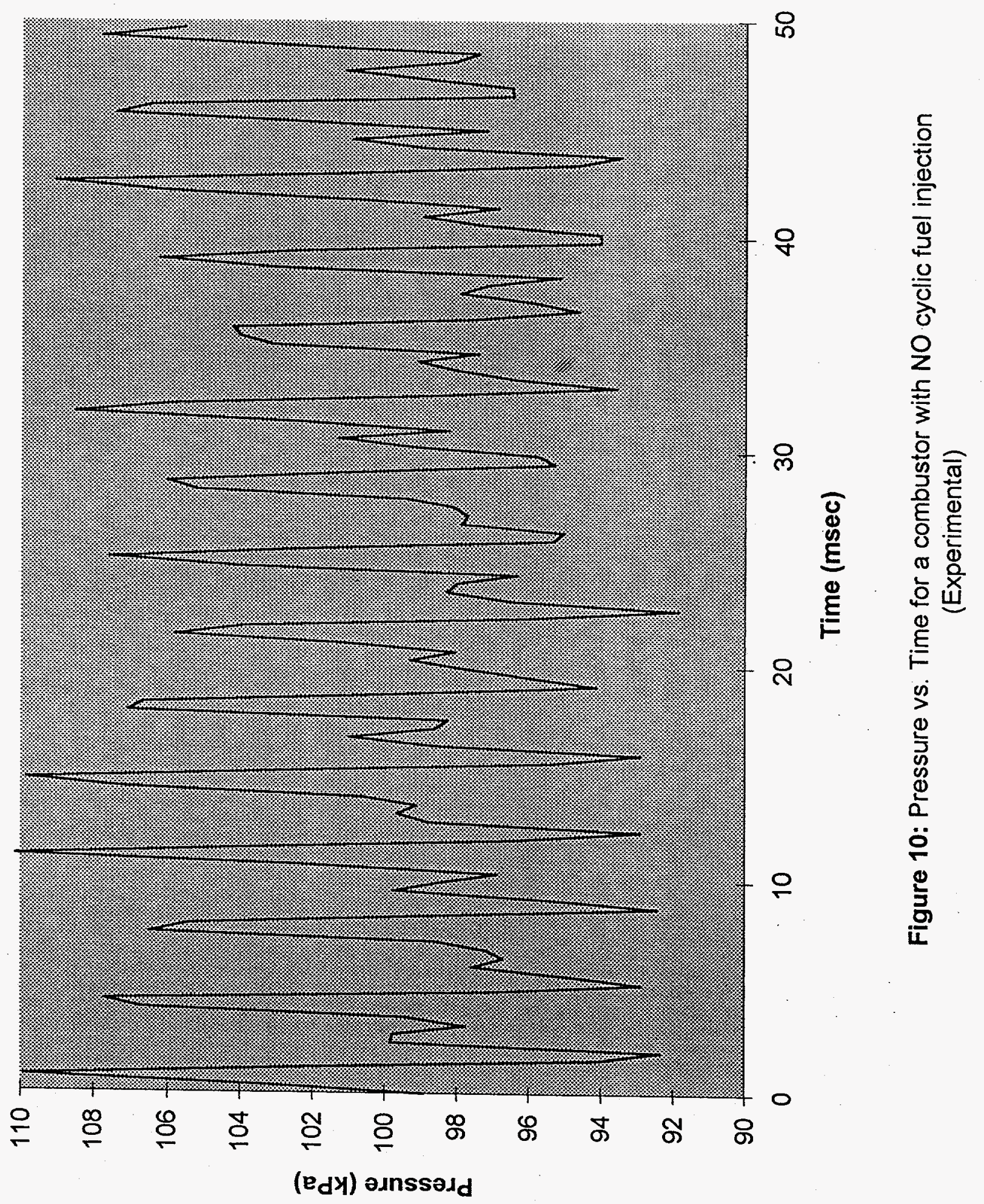




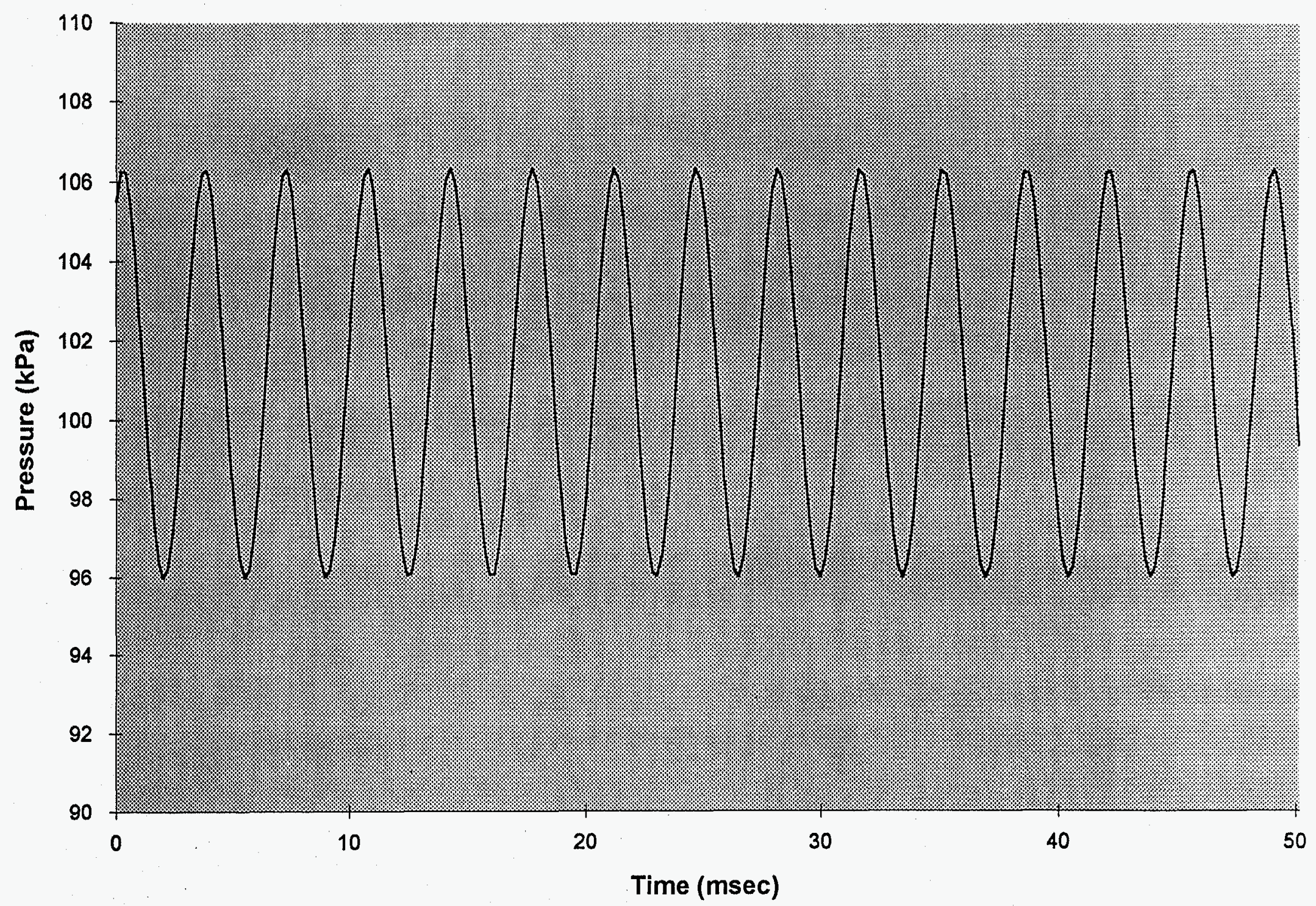

Figure 11: Pressure vs. Time for a combustor with NO cyclic fuel injection (Numerical) 


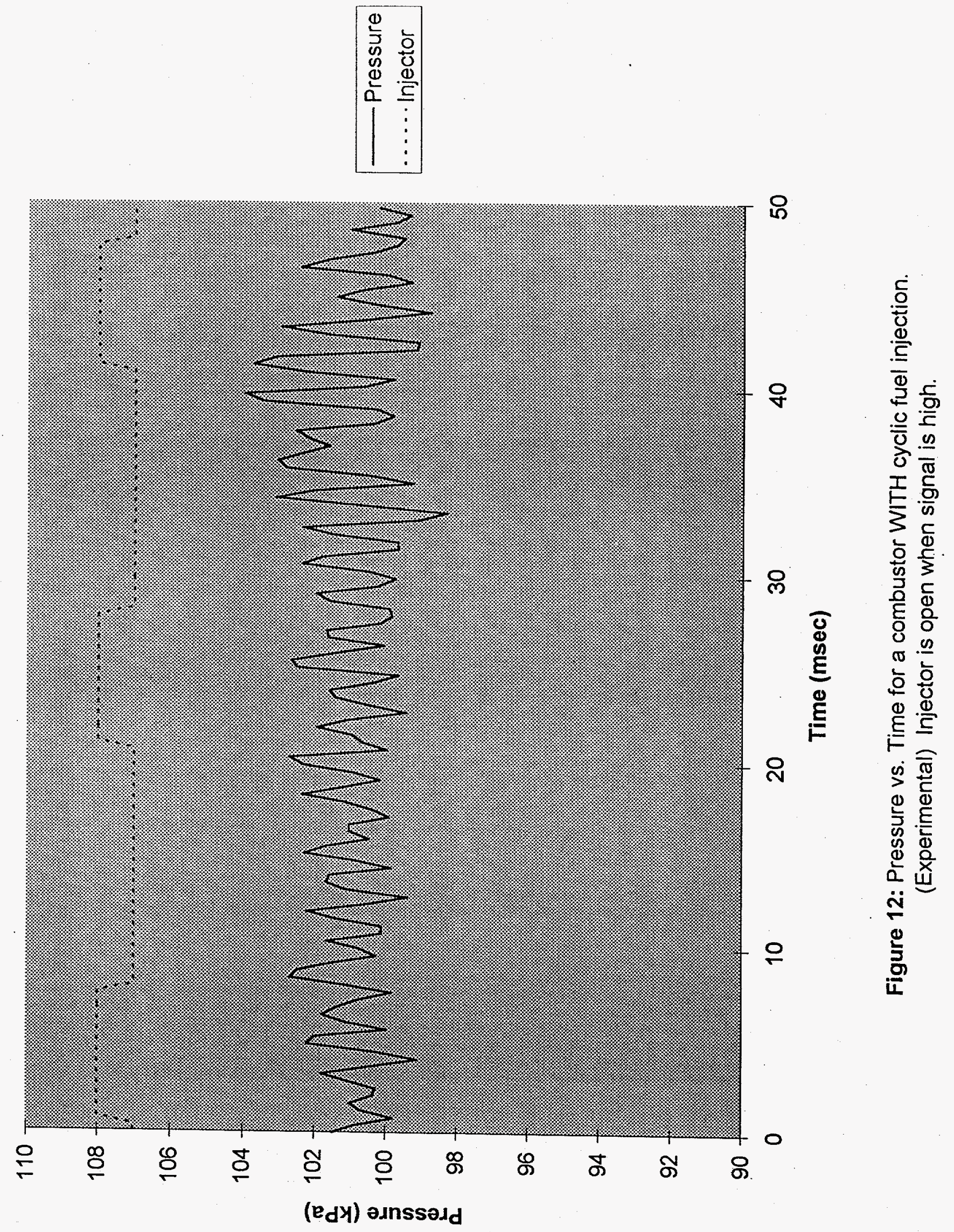



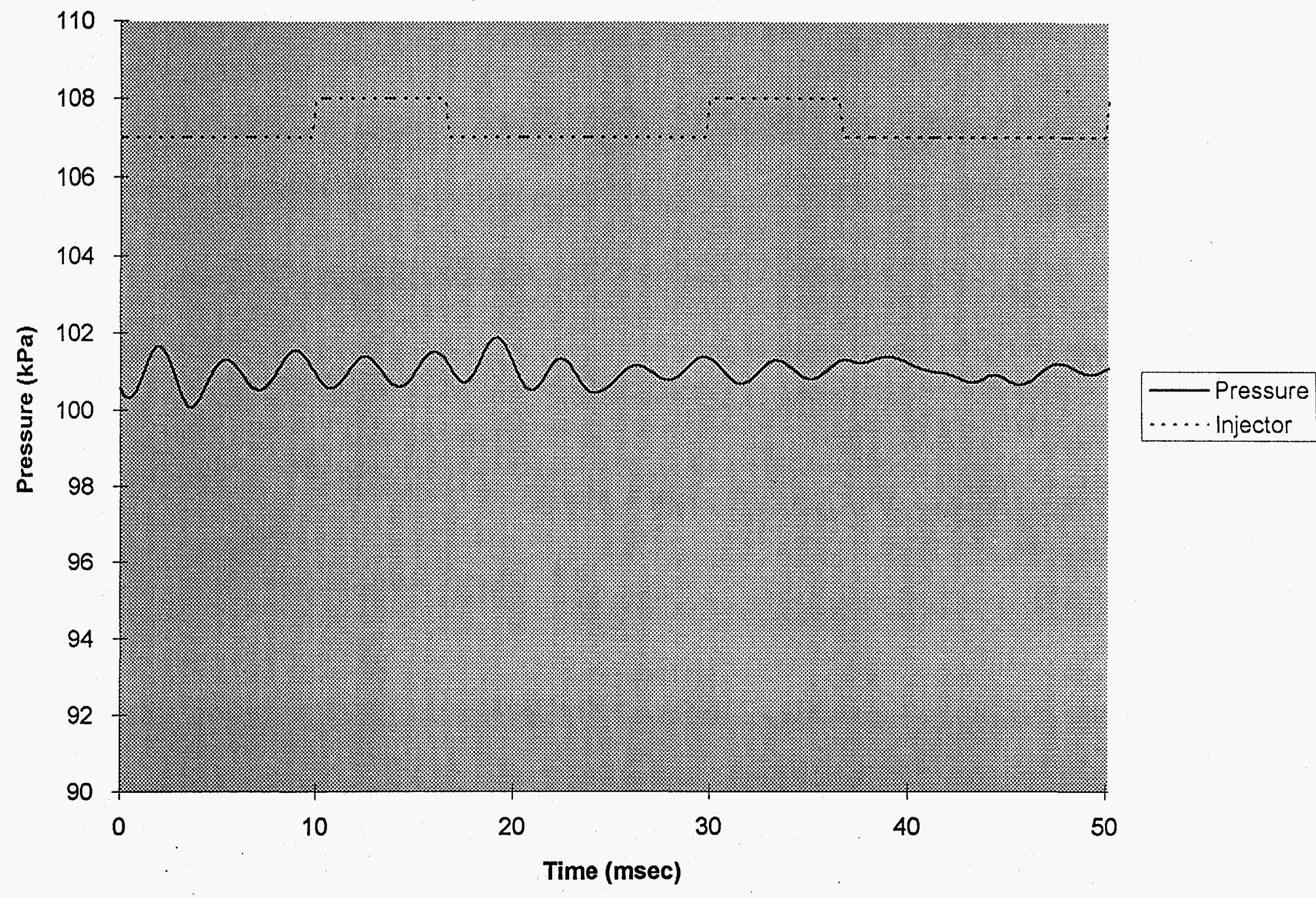

Figure 13: Pressure vs. Time for a combustor WITH cyclic fuel injection. (Numerical) Injector is open when signal is high. 

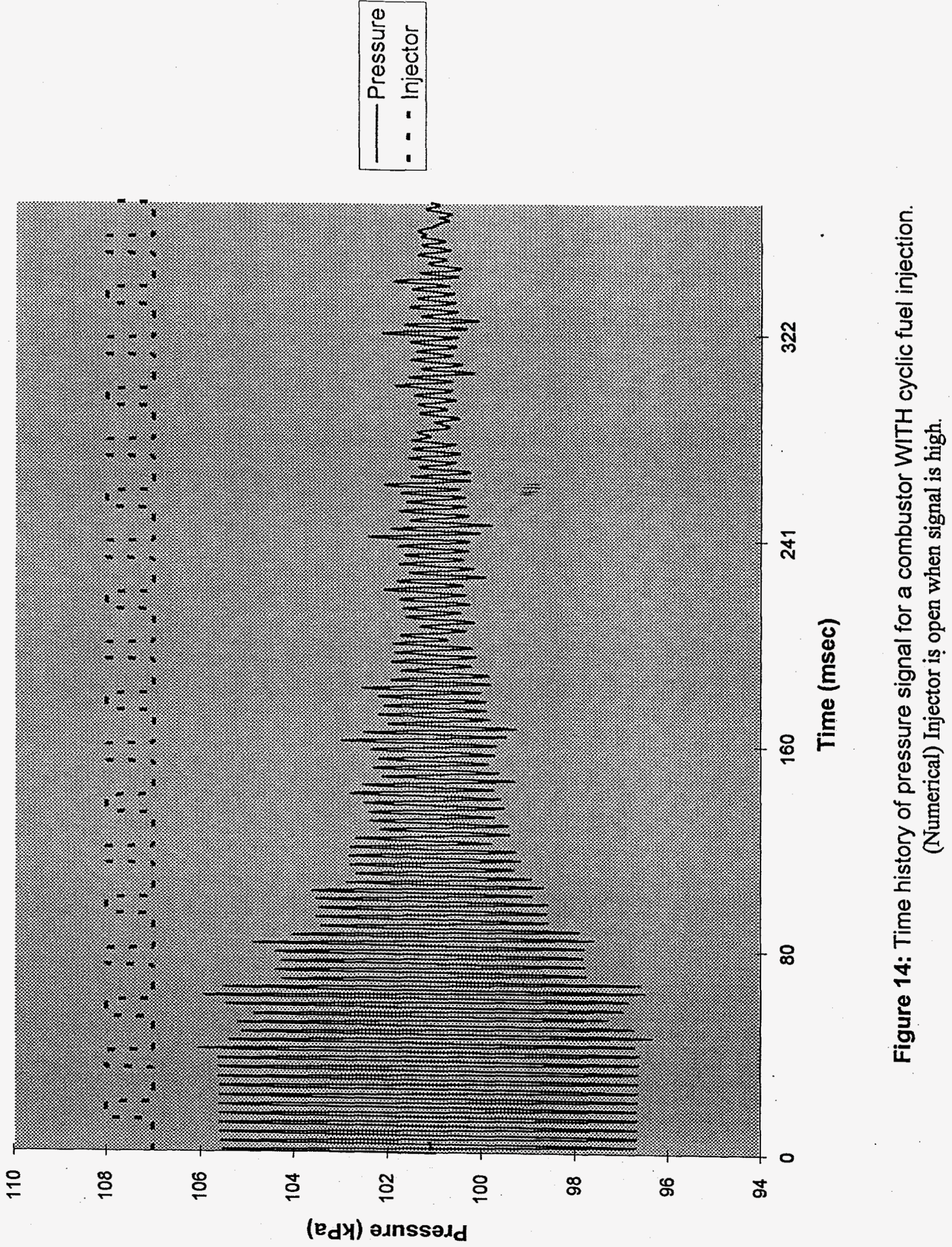

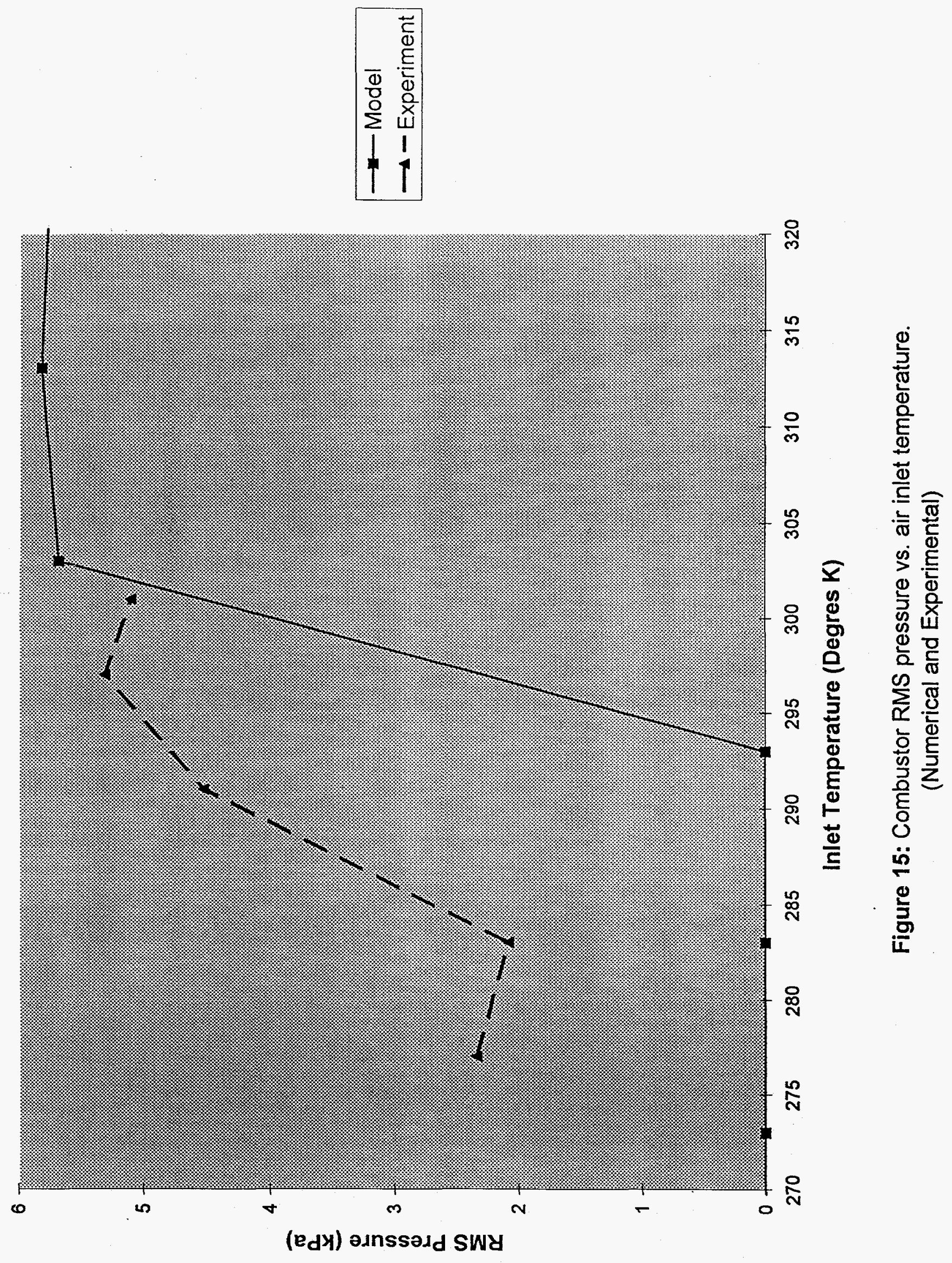


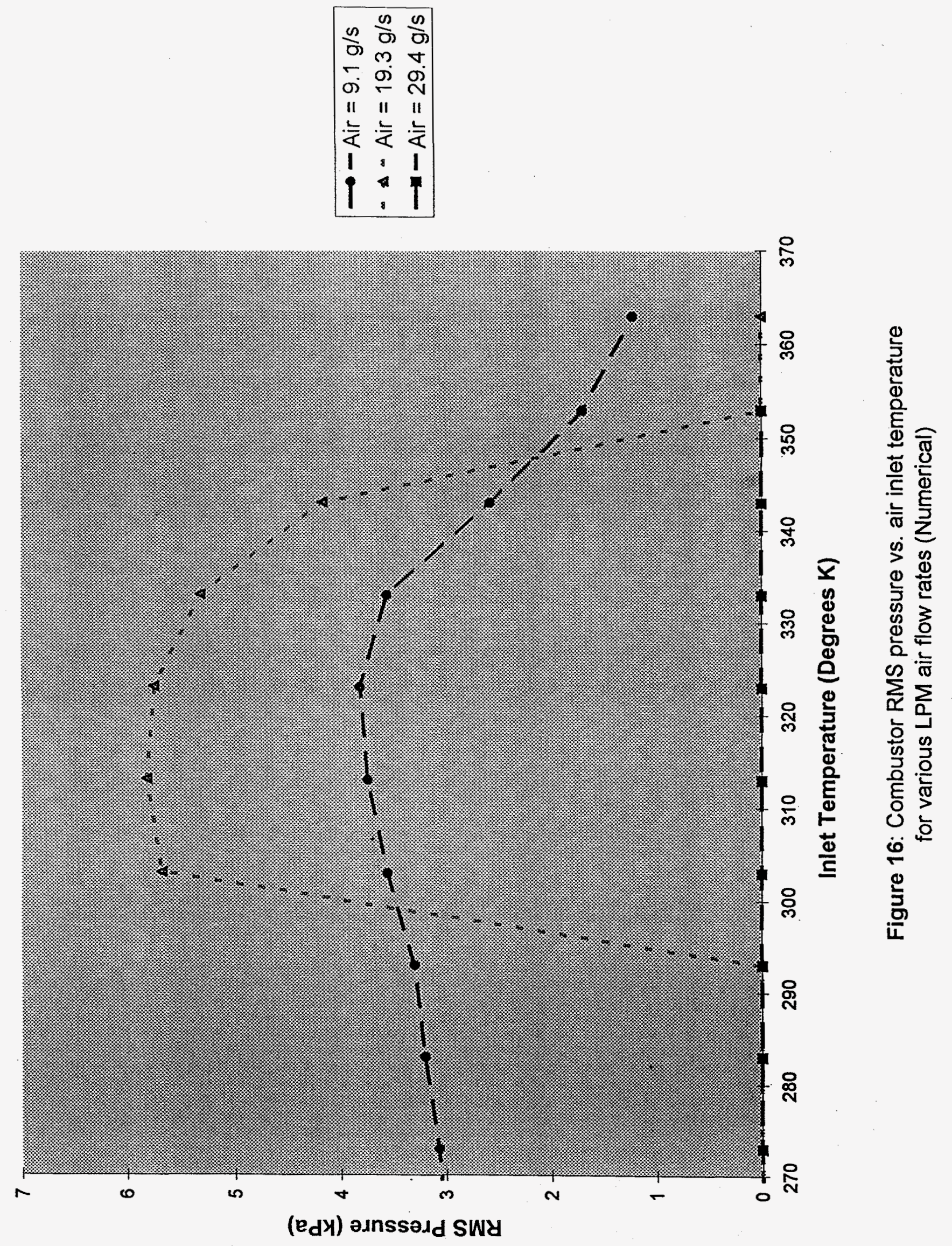



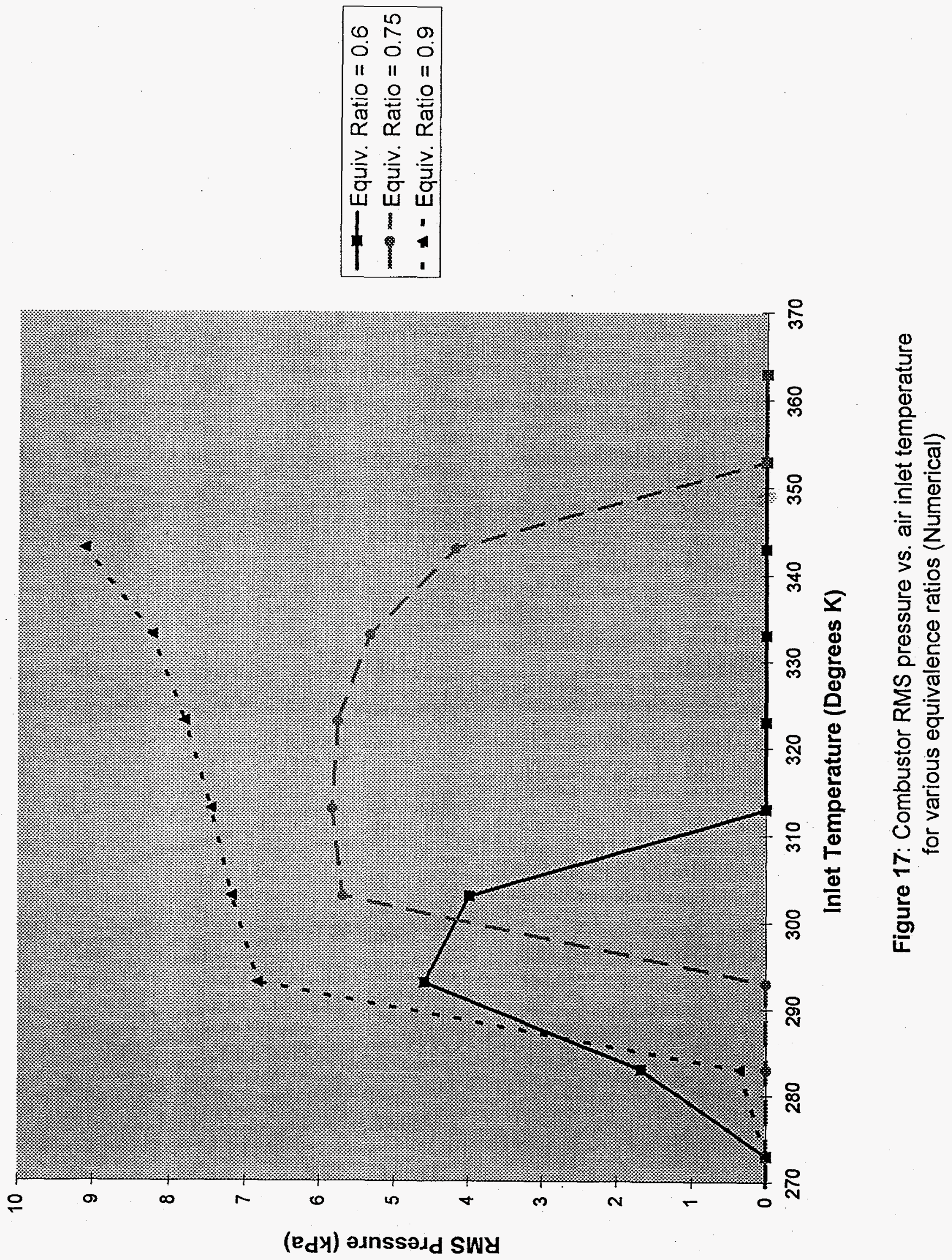